\title{
Mortality in COPD: Comparison of Different Predictors in Patients Seeking a Pulmonary Rehabilitation Program
}

\section{Mortalidade na DPOC: Comparação de Diferentes Preditores nos Pacientes que Procuram um Programa de Reabilitação Pulmonar}

\author{
Thamyres Spositon da Silva ${ }^{\mathrm{a}}$; Antenor Rodrigues ${ }^{\mathrm{b}}$; Juliana Fonseca Micheletib; Nidia Aparecida Hernandes ${ }^{\mathrm{c}}$; \\ Fabio Pittac; Karina Couto Furlanetto*a \\ ${ }^{a}$ Unopar, Stricto Sensu Graduate Program in Rehabilitation Sciences. PR Brazil. \\ ${ }^{b}$ State University of Londrina, Department of Physical Therapy, Research Laboratory in Pulmonary Physical Therapy. PR Brazil. \\ 'State University of Londrina, Stricto Sensu Graduate Program in Rehabilitation Sciences. PR Brazil. \\ *E-mail: karina.couto@kroton.com.br \\ Recebido em: 05/04/2019 \\ Aprovado em: 01/10/2019
}

\begin{abstract}
It is clinically relevant to identify isolated factors or multidimensional predictors of mortality in patients with Chronic Obstructive Pulmonary Disease (COPD). To compare different factors in the identification of patients classified as high risk of death and to identify the prognostic value of isolated factors against the BODE index. Patients were evaluated considering the factors associated with mortality: pulmonary function with forced expiratory volume (FEV1); body mass index (BMI); body mass index (LMWI); Incremental Shuttle Walk Test (ISWT) with estimation of maximal oxygen consumption (VO2max); six-minute walk test (6MWT); Medical Research Council scale; BODE index and sedentary time. Cut-off points previously associated with risk of death were used to calculate the proportion of patients at high risk of death. ROC curve analysis was used to test the prognostic value of each variable against the BODE index. A total of 162 patients ( 86 men, age $67 \pm 8$ years) were included. The proportions of patients classified as high risk ranged from 12.6 to $76.5 \%$ according to all eight factors analyzed (P $<0.05 \mathrm{vs}$ all). The area under the curve (AUC) of each factor analyzed against the BODE index indicated insufficient discriminative capacity $(0.26<$ AUC $<0.44)$. Conclusion: There is an expressive variability of patients classified as "high risk" according to each predictor factor. Moreover, the prognostic evaluation of the patient using the BODE index cannot be replaced by the assessment of a single predictive factor.
\end{abstract}

Keywords: Chronic Obstructive Pulmonary Disease, Mortality, Exercise.

\section{Resumo}

É clinicamente relevante identificar fatores preditores de mortalidade isolados ou multidimensionais em pacientes com Doença Pulmonar Obstrutiva Crônica (DPOC). O objetivo desse esuto foi comparar diferentes fatores na identificação de pacientes classificados em alto risco de morte e identificar o valor prognóstico de fatores isolados frente ao índice BODE. Foram avaliados pacientes quanto a fatores associado a mortalidade: função pulmonar com a medida do volume expiratório forçado (VEF); indice de massa corpórea (IMC); indice de massa magra corporal (IMMC); Incremental Shuttle Walk Test (ISWT) com a estimativa do consumo máximo de oxigênio (VO, máx); teste de caminhada de seis minutos (TC6min); escala Medical Research Council; indice BODE e tempo sedentário. Pontos de corte previamente associados com mortalidade foram utilizados para calcular a proporção de pacientes em alto risco. Análise de curva ROC foi utilizada para testar o valor prognóstico das variáveis isoladas frente ao BODE. Foram incluídos 162 pacientes (86 homens, idade $67 \pm 8$ anos). As proporções de pacientes classificados em alto risco variaram de $12,6 \%$ até $76,5 \%$ de acordo com os oito fatores analisados ( $P<0,05$ vs todos). A área sob a curva (AUC) desses fatores testados isoladamente frente ao índice BODE indicou insatisfatória capacidade discriminativa $(0,26<A U C<$ 0,44). Existe uma variabilidade expressiva na proporção dos pacientes classificados como "alto risco" de acordo com cada fator preditor de mortalidade. Além disso, a avaliação prognóstica do paciente obtida com o indice BODE não pode ser substituída pela avaliação de um único fator preditor.

Palavras-chave: Doença Pulmonar Obstrutiva Crônica. Mortalidade. Exercício.

\section{Introduction}

Patients with Chronic Obstructive Pulmonary Disease (COPD) have clinical pulmonary and systemic manifestations ${ }^{1.2}$. In addition to respiratory impairment marked by a sensation of dyspnea due to pulmonary hyperinflation and/or abnormalities in gas exchange, other systemic changes resulting from the disease are also observed. Patients with COPD frequently present greater oxidative stress and increased proinflammatory state. In addition, clinical changes as the peripheral muscle dysfunction, low exercise capacity, physical inactivity, changes in weight and body composition and reduction of respiratory and peripheral muscle strength are present in those patients ${ }^{2}$

Based on current scientific literature, some of these clinical changes that affect the physical health of patients with COPD are recognized as factors that interfere directly and indirectly on mortality in this population. These factors are called "predictors of mortality" and allow the classification of patients at high or low risk of mortality.

Among the several variables recognized as predictors of mortality, the airflow obstruction (graded by end-expiratory volume in the first second $\left.\mathrm{FEV}_{1}\right)^{3}$, the sensation of dyspnea in daily life (assessed by the modified Medical Research Council scale $-m \mathrm{MRC})^{4}$, the depletion of fat-free mass ${ }^{5}$, the decrease 
of body mass index ${ }^{6}$, the low capacity of submaximal exercise both submaximal (i.e., distance travelled in the six-minute walk test[TC6min] and maximum oxygen consumption $\left.\left[\mathrm{VO}_{2} \max \right]\right)^{7}$, and, more recently, the sedentary behavior ${ }^{8}$, are considered factors that increase the risk of death in this population. Multidimensional indices that use these factors in combination, as for example, BODE index, whose score ranges from 0 to 10 ( from English $B$ - body mass index; 0airflow obstruction; $D$-dyspnea; E- exercise capacity) also have their impact on the identification of a higher risk of death demonstrated in these patients ${ }^{9}$.

Due to all the alterations previously mentioned and the increase in the prevalence of COPD in all over the world, estimates rank COPD as possibly the third most common cause of death in the world in the year $2030^{10}$. Even though widely recognized as factors directly related to higher death in this population, the proportion of patients identified at high risk of death is not known according to each predictor. Moreover, the prognostic value of each predictor (isolatedly) before the BODE index was also not investigated in patients with COPD who seek a pulmonary rehabilitation program. This literary gap impacts negatively on the recognition of the factors that most affect these patients, hindering the development of means to provide greater survival to the same. Thus, this study aims to compare different predictors of death in the identification of patients at high risk of death"; and identify the prognostic value of isolated variables before the BODE index. Thus, it is expected to express the variability of patients classified in the category "high risk" in accordance with the criterion of choice (predictor) and identify if a composite index could be replaced by a single variable, facilitating the prognostic assessment.

\section{Material and Methods}

\subsection{Sample and study design}

This was a cross-sectional study with a convenience sample composed of patients diagnosed with COPD according to the criteria of the Global Initiative for Chronic Obstructive Lung Disease (GOLD) ${ }^{1}$. The individuals were initially evaluated to participate in a research project that offered treatment with physical training, in the Laboratory of Research in Pulmonary Physical Therapy (LFIP), State University of Londrina (UEL), Paraná. Data collected in the initial evaluation between 2006 and 2014 were used in the study herein. The data were analyzed retrospectively. In addition, the patients were also classified in group of high-risk or low risk, according to the scientific evidence regarding each one of the predictors of mortality in COPD.

The inclusion criteria were as follows: diagnosis of COPD in accordance with international standards ${ }^{1}$; absence of exacerbations for at least three months; absence of osteoneuro-muscle alterations that could interfere or limit the proposed treatment; and not having participated in pulmonary rehabilitation program in the last year.
All participants signed a Free and Informed Consent Form prior to the beginning of the study, which was approved by the Research Ethics Committee of UEL, under the number $123 / 09$.

\subsection{Assessments}

The patients were evaluated regarding the pulmonary function by means of spirometry (Espirobank G, MIR, Italy) ${ }^{11}$ and the reference equations for the Brazilian population were used $^{12}$, and the post-bronchodilator evaluation was considered.. Concerning the pulmonary function, FEV values below $31 \%$ (for males) or below 26\% (for females) increases the risk of death in COPD, and these cut-off points were considered in this study ${ }^{3}$.

Body composition was assessed through the test of electrical bioimpedance (Biodynamics model 310, United States $)^{13}$. Concerning the predictive power of body composition mortality, values of body mass index (BMI) below $25 \mathrm{~g} / \mathrm{m}^{2}$ and lean body mass (LBM) below $15 \mathrm{~kg} / \mathrm{m}^{2}$ (for female patients) or $16 \mathrm{~kg} / \mathrm{m}^{2}$ (for males) were considered ${ }^{5.6}$.

The functional exercise capacity was evaluated by means of TC6min in accordance with international recommendations ${ }^{14}$, and the predicted values calculated from the values described for the Brazilian population ${ }^{1}$ It was considered that values of TC6min below $350 \mathrm{~m}$ increases the risk of death in COPD patients ${ }^{7}$.

For the assessment of maximum exercise capacity the Incremental shuttle walking test (ISWT) was performed, in accordance with international standardization ${ }^{14,16}$ using national reference values ${ }^{17}$. $\mathrm{VO}_{2} \max$ is estimated from the equation described in the literature ${ }^{15}$. It was considered that values of $\mathrm{VO}_{2}$ below $350 \mathrm{~m}$ increases the risk of death in COPD patients ${ }^{7}$.

In order to evaluate the sensation of dyspnea during the daily life, the MRC scale was used ${ }^{18}$. The patient chooses an item, between 1 and 5, which corresponds to how much dyspnea limits their daily life. Subsequently, the results of the MRC scale were reduced at one point, so that the considered interval was between 0 and 4 , the same used to identify risk of death (modified MRC - mMRC). Patients characterized with $\geq 2$ points in this modified scale present a higher risk of death ${ }^{4}$.

Sedentary lifestyle was assessed by means of the SenseWear Armband (Body Media, United States [SAT]), which is a multi-sensor device comprising an accelerometer and physiological sensors validated for patients with COPD $^{19.20}$. Time spent on activities of different intensities were measured for two days ${ }^{21}$ and the average time spent on activities with lower intensity to 1.5 MET was used in order to classify the individual in a sedentary or non-sedentary ${ }^{22}$. It was considered that patients with COPD who spend $\geq 8: 30$ hours/day in sedentary activities with an intensity below 1.5 MET (TS $<1.5 \mathrm{MET})$ have a higher risk of death ${ }^{8}$.

The BODE index is a multidimensional scale, used as an 
indirect predictor of risk of death for patients with COPD. Four factors are used for the calculation of BODE: índice de massa corporal (BMI: Body mass index; (B), degree of obstruction of the airways with $\mathrm{FEV}_{1}$ in $\%$ of predicted values (airflow obstruction; O), dyspnea by means of the mMRC scale (dyspnea; (D) and capacidade ao exercicio (exercise capacity; (E) measured by means of TC6min. High rates (i.e. $\geq 7$ points) are associated with an increased risk of death ${ }^{9}$.

\subsection{Statistical analysis}

The data distribution was analyzed by the Shapiro-Wilk test. The comparisons of the number of patients classified as high risk among each variable predictive of mortality were performed by univariate Chi-square test. In a subpaired analysis with the 82 individuals who possessed all the complete data, the Cochran's Q test and its respective posttest were used to compare the number of patients who were or not at increased risk according to each studied variable. For the correlations analysis the Pearson or Spearman correlation coefficients were used, according to the normality in the data distribution. Finally, in order to identify the sensitivity and specificity of the variables, the BODE index was used as a reference for prognosis and the ROC curve analysis was performed to identify whether each of the variables could be considered, in isolation, a good mortality predictor. The statistical significance was defined as $P<0.05$. The data were analyzed using the statistical software SPSS 21 and the graphics were made with the GraphPad Prism 6.0.

\section{Results and Discussion}

A total of 162 patients diagnosed with COPD were included in the study. Of this total, one patient did not perform the post-bronchodilator pulmonary function and 69 were not evaluated by the ISWT by logistical issues. Two patients had incomplete data of LBM and two of the mMRC scale; thus, three patients did not have the BODE index calculated due to incomplete data. In addition, 24 patients did not have their sedentary time assessed by technical problems with the physical activity monitor. Of the 162 patients evaluated in this study, 82 had complete data for all assessments. Both samples were similar regarding the anthropometric characteristics and all variables analyzed to identify the risk of mortality. $(P>0.05$ for all).

The sample was composed of patients with a mean age of 67 years, classified according to the BMI between normal and overweight. In addition, the patients included in the study presented from mild to very severe obstruction to airflow, according to the GOLD criteria ${ }^{1}$. The patients presented a submaximal exercise capacity relatively preserved, being that only 54 patients showed the TC6min in percentage of the predicted $<80 \%$; however, with greater involvement of the maximum exercise capacity measured by $\mathrm{VO}_{2}$ max estimated by means of the ISWT. Furthermore, the patients were symptomatic during the performance of daily living activities, assessed by the mMRC scale. The complete data on the sample characterization are described in Table 1.

Table 1 - Characterization of patients included in the study

\begin{tabular}{|c|c|}
\hline Variable & $n=162$ \\
\hline Age (years) & $67 \pm 8$ \\
\hline Weight (Kg) & $67[55-79]$ \\
\hline Height (m) & $1.60 \pm 0.08$ \\
\hline BMI $\left(\mathrm{Kg} / \mathrm{m}^{2}\right)$ & $26[22-31]$ \\
\hline LBM $\left(\mathrm{Kg} / \mathbf{m}^{2}\right)$ & $16.3 \pm 2.2$ \\
\hline FVC (L) & $2.14[1.66-2.70]$ \\
\hline FVC (\%pred) & $67 \pm 16$ \\
\hline FEV $_{1}(\mathrm{~L})$ & $1.07[0.80-1.47]$ \\
\hline FEV (\%pred) & $44[31-57]$ \\
\hline FEV / / FVC & $53[42-64]$ \\
\hline TC6min (m) & $448[401-508]$ \\
\hline TC6min (\%pred) & $86[76-94]$ \\
\hline ISWT (m) & $420[320-520]$ \\
\hline $\mathbf{V O}_{2}$ máx $(\mathrm{ml} / \mathrm{min})$ & $661 \pm 153$ \\
\hline $\mathbf{V O}_{2}$ máx (\%pred) & $69 \pm 26$ \\
\hline mMRC (0 - 4) & $3[3-2]$ \\
\hline BODE (0 - 10) & $5[3-6]$ \\
\hline
\end{tabular}

BMI Body mass index; LBM: Body mass index; FVC: Forced vita capacity; $\mathrm{FEV}_{1}$ : Forced expiratory volume in the first second; TC6min: six-minute walk test; ISWT: Incremental shuttle walk test; $\mathrm{VO}_{2}$ : Maximum oxygen consumption; mMRC: Modified Medical Research Council; BODE: $B$ - body mass index; $O$ - airflow obstruction; $D$ dyspnea; $E$ - exercise capacity; TS $<1,5$ MET: Sedentary time $<1.5$ metabolic equivalent. Data described as mean \pm standard deviation or median [interquartile range $25-75 \%$ ].

Source: Research data.

When analyzed the proportion of patients classified as high risk according to the cut-off point for each variable predictive of mortality evaluated, a great variability was found in the results (Table 2). The variable that showed the greatest proportion of individuals with increased risk of death was the sensation of dyspnea in daily life (mMRC), in which $76.5 \%$ of the patients were classified as high risk.

Table 2 - Proportion of individuals classified as high or low risk of death

\begin{tabular}{|l|c|c|c|c|}
\hline Predictor & $\mathbf{n}$ & Cut-off point & $\begin{array}{c}\text { High } \\
\text { risk* }^{*}\end{array}$ & Low risk* $^{*}$ \\
\hline BMI, n(\%) & 162 & $<25 \mathrm{~kg} \cdot \mathrm{m}^{-2}$ & $73(45)$ & $89(55)$ \\
\hline LBM, n(\%) & 160 & $\begin{array}{c}\mathrm{H}:<16 / \\
\mathrm{M}:<15 \mathrm{~kg} \cdot \mathrm{m}^{-2}\end{array}$ & $58(36.3)$ & $102(63.7)$ \\
\hline FEV $\mathbf{1}(\%)$ & 161 & $\begin{array}{c}\mathrm{H}:<31 / \\
\mathrm{M}:<26 \% \text { pred }\end{array}$ & $33(20.5)$ & $128(79.5)$ \\
\hline TC6min, n(\%) & 162 & $<350$ meters & $20(12.3)$ & $142(87.7)$ \\
\hline VO, máx n(\%) & 93 & $<41 \%$ pred & $17(18.3)$ & $76(81.7)$ \\
\hline mMRC, n(\%) & 160 & $\geq 2$ pts & $124(76.5)$ & $36(23.5)$ \\
\hline BODE, n(\%) & 159 & $\geq 7$ pts & $20(12.6)$ & $139(87.4)$ \\
\hline $\begin{array}{l}\text { TS }<\mathbf{1 , 5 M E T ,} \\
\text { n (\%) }\end{array}$ & 138 & $\geq 8 \mathrm{~h} 30$ & $44(31.9)$ & $94(68.1)$ \\
\hline
\end{tabular}

H: Men; M: women. BMI Body mass index; LBM: Body mass index; $\mathrm{FVC}_{1}$ : Forced expiratory volume in the first second; TC6min: six-minute walk test; $\mathrm{VO}_{2}$ : Maximum oxygen consumption; mMRC: Modified Medical Research Council; BODE: $B$ - body mass index; $O$ - airflow 
obstruction; D - dyspnea; $E$ - exercise capacity; TS < 1,5 MET: Sedentary time $<1.5$ metabolic equivalent. *Data described as absolute and relative values $(\%)$.

Source: Research data.

In contrast, the smallest proportion of individuals classified as high risk was obtained in accordance with the criterion of exercise capacity, as assessed by the TC6min, in which only $12 \%$ of the patients had a higher risk of death. There was a significant difference for almost all the variables between the proportion of individuals classified as high or low risk. Only the variable BMI identified similar proportions ( $46 \%$ in high risk; $p=0.21$ ). In the paired analysis including only those 82 patients with complete data (Figure 1), the comparison of the classifications of patients among the eight variables was statistically different $(P<0.05)$. It was observed that the classification of risk of death using the mMRC reached the highest proportion of patients with high risk of death $(P<0.05$ for all). The correlations among the variables predictive of mortality evaluated in this study were also investigated (Table 2). A variation was observed from weak to strong magnitude in the correlations $(0.181 \leq \mathrm{r} \leq 0.797)$. The strongest correlation $(r=0.797)$ was found between the variables of body composition (i.e. BMI and LBM). The other variables predictive of mortality showed significant correlations among themselves in low or moderate magnitude $(\mathrm{r} \leq 0.551)$. The sensitivity and specificity of each predictor of mortality analyzed isolatedly before BODE index were not significant because the results of AUC varied between 0.26 and 0.44 .

Figure 1- Comparison of the proportion of patients classified as high or low risk of death in accordance with the cut-off point determined for each predictor of mortality in patients with COPD

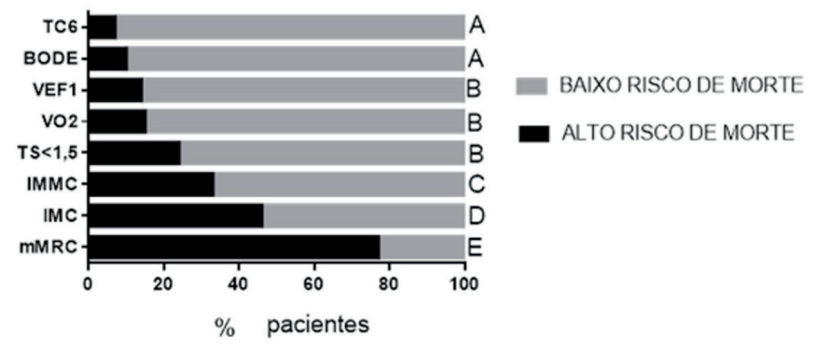

TC6min: Six-minute walk test; BODE: index that includes the variables, from English: B - body mass index (índice de massa corpórea); O airflow obstruction (obstrução ao fluxo aéreo); D - dyspnea (dispneia); E - exercise capacity (capacidade de exercício). VO2máx: Maximum oxygen consumption; $\mathrm{FVC}_{1}$ : Forced expiratory volume in the first second; TS $<1,5 \mathrm{MET}$ (time spent in sedentary activity with intensity $<1.5$ - metabolic equivalent -MET) LBM: lean body mass index; BMI: body mass index; mMRC: scale modified from the Medical Research Council. A: $\mathrm{p}<0.05$ vs. BMI, LBM, mMRC, TS $<1.5$ MET. B: $\mathrm{p}<0.05$ vs. BMI, mMRC. C: $p<0.05$ vs. BMI, LBM, mMRC. D: $p<0.05$ vs. TC6min. E: $p<0.05$ vs. FEV1, TC6min, mMRC, BODE. F: $p<0.05$ vs. TC6min, BODE, VO2max, FEV1, mMRC. G: $\mathrm{p}<0.05$ vs. TC6min, BODE, VO2max, FEV1, TS $<1.5$ MET, LBM, BMI.

Source: The authors.
The present study identified a significant variability in the classification of the risk of death in patients with COPD according to the choice of the predictor factor. The proportions of patients identified in the categories high and low risk of death were very different, especially when the mMRC scale was used, which ranked the highest number of patients at increased risk of death $(76.5 \%)$ in comparison with the other analyzed variables (i.e., $\mathrm{BMI}, \mathrm{LBM}, \mathrm{FEV}_{1}, \mathrm{VO}_{2} \max , \mathrm{TS}<1,5 \mathrm{MET}$, BODE index and TC6min). In addition, it is suggested that the evaluation of the prognostic value of the patient through the BODE index cannot be replaced by a single variable. In fact, a greater ease for clinical practice would exist if the evaluation of an isolated variable was sensitive and specific enough to predict the prognosis of patients with COPD in the same way that the BODE index. However, the assessment of pulmonary and systemic components is unmatched in the case of prognostic value.

Dyspnea is defined as a subjective experience of respiratory discomfort that can influence the health-related quality of life $^{23}$. In addition, it is the most common and characteristic symptom found in patients with $\mathrm{COPD}^{1}$. Due to being so present in the lives of these patients, the sensation of dyspnea, is considered one of the main reasons that lead them to seek pulmonary rehabilitation programs ${ }^{23}$. Gouzi and collaborators identified that the dyspnea is one of the symptoms that precede the diagnosis of $\mathrm{COPD}^{24}$. In the same study, the authors demonstrated in a sample of 129 patients that the sensation of dyspnea started with a median age of 49 years, then the patients were diagnosed (median of 53 years) and started the PR program with approximately 58 years. These facts can assist in the understanding of the high prevalence of patients classified at higher risk of death in accordance with the mMRC scale in this study.

In contrast, $45 \%$ of the patients were classified as increased risk of death according to the cut-off point for BMI, and $36 \%$ according to the cut-off point of the LBM. Obesity is becoming more common in this population, moreover, it is known that the evolution of COPD can bring innumerable complications that affect the nutritional state of patients with $\mathrm{COPD}^{25}$, as for example, the influence of drugs, which may have a negative impact due to loss of appetite ${ }^{26}$. These changes of nutritional status contributes to increased mortality, which predisposes these patients a series of serious complications, including, respiratory failure, heart failure and muscular atrophy.

Furthermore, patients with COPD usually do little physical activity with moderate or high intensity in everyday life $\mathrm{e}^{23}$. The present study showed that $31.9 \%$ of the patients analyzed have a sedentary time $\geq 8.5$ hours/day, which classifies them as patients with four times more likely to die in comparison with the non-sedentary patients ${ }^{8}$. It is known that the sedentary lifestyle results in deleterious effects to the health of an individual regardless of the level of physical activity performed, and this applies for different populations, including patients with $\mathrm{COPD}^{22.27}$. Despite this, strategies to 
reduce sedentary lifestyle still need to be investigated in the scientific community.

Additionally, patients with COPD commonly relate dyspnea in daily life, present a reduction in muscle strength and aerobic capacity, thus, become increasingly inactive, which characterizes the vicious cycle of $\mathrm{COPD}^{23}$. In agreement with these findings, the present study found a moderate correlation (Table 3) between the variables of time sedentary and exercise capacity (i.e., TC6min; $r=-0.551$ ). In fact, the large proportion of individuals with COPD are not able to meet the minimum recommended amount of daily physical activity ${ }^{8.21}$.

Table 3 - Correlation among the predictors of mortality in patients with chronic obstructive pulmonary disease

\begin{tabular}{|l|c|c|c|c|c|c|c|}
\hline & $\begin{array}{c}\text { BMI (Kg/ } \\
\left.\mathbf{m}^{2}\right)\end{array}$ & $\begin{array}{c}\text { LBM (Kg/ } \\
\left.\mathbf{m}^{2}\right)\end{array}$ & $\begin{array}{c}\text { FEV } \\
(\% \text { pred.) }\end{array}$ & $\begin{array}{c}\text { TC6min. } \\
(\mathbf{m} .)\end{array}$ & $\begin{array}{c}\text { VO máx } \\
(\% \text { pred) }\end{array}$ & $\begin{array}{c}\text { mMRC } \\
\text { (pts.) }\end{array}$ & $\begin{array}{c}\text { BODE } \\
\text { (pts.) }\end{array}$ \\
\hline LBM (Kg/m $)$ & $0.797^{*}$ & - & - & - & - & - & - \\
\hline FEV (\%pred) & 0.282 & $0.188^{*}$ & - & - & - & - & - \\
\hline TC6min (m) & -0.137 & -0.011 & $0.298^{*}$ & - & - & - & - \\
\hline VO, máx (\%pred) & 0.038 & -0.050 & $0.488^{*}$ & $0.424^{*}$ & - & - & - \\
\hline mMRC (pts.) & -0.044 & -0.143 & $0.362^{*}$ & $-0.402^{*}$ & -0.130 & - & - \\
\hline BODE (pts.) & $0.255^{*}$ & $-0.221^{*}$ & $0.506^{*}$ & $-0.246^{*}$ & $-0.248^{*}$ & $0.309^{*}$ & - \\
\hline TS<1.5MET(h/day) & $0.181^{*}$ & 0.197 & $0.225^{*}$ & $-0.551^{*}$ & $-0.228^{*}$ & $0.254^{*}$ & 0.118 \\
\hline
\end{tabular}

BMI Body mass index; LBM: Body mass index; $\mathrm{FVC}_{1}$ : Forced expiratory volume in the first second; TC6min: six-minute walk test; $\mathrm{VO}_{2}$ máx: Maximum
oxygen consumption; mMRC: Modified Medical Research Council; BODE: $B$ - body mass index; $O$ - airflow obstruction; $D$ - dyspnea; $E$ - exercise capacity; TS $<1.5 \mathrm{MET}$ : Sedentary time $<1.5$ metabolic equivalent. Data were analyzed with the Spearman or Pearson correlation coefficient according to the normality test.

Source: Research data.

The present study identified a lower proportion of patients with imminent risk of death regarding exercise capacity, $12.3 \%$ when analyzed on the cut-off point for TC6min and $18.3 \%$ when referring to the $\mathrm{VO}_{2} \max$. These results reflect the great variability in the identification of the prognosis from the choice of different variables. In the present study, only 20 patients achieved a TC6 below 350 meters, however, approximately one third of the sample presented TC $6<80 \%$ predicted based on Brazilian equations. In fact, the cutoff points relating the exercise capacity tests were described from studies developed in the European population ${ }^{7}$. Recently, Rodrigues and collaborators have suggested in a cluster analysis that the cut-off point of 427 meters in the TC6 is more sensitive to predict mortality in Brazilian patients with COPD than the cut-off point widely used in isolation and also suggested by BODE (e.g. 350 meters ${ }^{28}$. In addition, Brazilian patients with COPD have a greater exercise capacity then= patients from other regions of the world ${ }^{29}$, which might justify the lower proportion of individuals with higher risk of death. The same occurred when the BODE index was used.

When it comes to the main manifestation of airflow obstruction in COPD (i.e. reduction in $\mathrm{FEV}_{1}$ ), studies show that $\mathrm{FEV}_{1}$ has a limited capacity for the prediction of exercise capacity, quality of life and the sensation of dyspnea in these patients. The weak correlations found in the present study support these findings among the variables cited above (Table 3). In spite of such importance for the diagnosis and classification of $\mathrm{COPD}^{1}$, a prevalence in the high risk group of only $\sim 20 \%$ of patients was observed in the present study according to $\mathrm{FEV}_{1}$. However, the number of patients with lighter and more serious impairment than $\mathrm{FEV}_{1}$ (i.e., GOLD I and IV) should be taken into consideration in the interpretation of the results presented here, since only one patient GOLD I $(1 \%)$ and 33 patients GOLD IV $(20 \%)$ were included in this study.

When it comes to the BODE index it was observed that only $12.6 \%$ of patients were at increased risk of death in this sample. The patients in the present study were associated with BMI between normal and overweight, obstruction of the airflow between moderate and severe, and exercise capacity relatively preserved. It is worth mentioning that the performance at the walking test contributes with 3 points in the calculation of the variation of the BODE index and that none of the patients walked less than 149 meters, i.e., the cutoff point suggested by Celli and collaborators to identify the worst score in the BODE index from the $\mathrm{TC}^{9}$. In addition, when the seven variables predictive of mortality were tested isolatedly before the BODE index, it was identified that no variable showed sensitivity and specificity sufficient to replace the use of the BODE index in the evaluation of patients with COPD. Previous studies identified that the variables in question have predictive power regardless of mortality ${ }^{3-9}$, however, the prognostic power of each one of them, does not discriminate against individuals of the same way that the BODE index.

Although only one patient GOLD I was included, it is believed that this study used a sample that reflects the main characteristics of patients with COPD who seek a pulmonary rehabilitation program in Brazil. Patients GOLD I usually are asymptomatic, and of course they do not seek a pulmonary rehabilitation program for treating the disease at that moment, however, scientific evidences suggest that 
pulmonary rehabilitation is also beneficial for patients GOLD $\mathrm{I}^{1}$, suggesting that this pattern of behavior should ideally be different. A limitation of this study was the fact that some patients have not performed all tests proposed and therefore, a sub-analysis with 82 patients was performed to compare the proportions of 8 prognostic evaluated factors. Another limitation concerns the assessment tool chosen for the analysis of body composition and the $\mathrm{VO}_{2} \max$. Finally, although the majority of patients present degree of obstruction from moderate to severe, the exercise capacity relatively preserved in patients resulted in a lower classification of risk of death with the use of exercise tests and consequently of the BODE index. There is, therefore, a great variability in classification of patients with high risk of death from cut-off points established beforehand.

\section{Conclusion}

The present study showed that the variable chosen as a predictor of risk of death in patients with COPD identifies very different proportions of patients at high risk of death. In addition, the prognostic value identified by means of a composite index (i.e., the BODE index) cannot be replaced by the use of variables predictive of mortality in isolatedly.

\section{Acknowledgments}

To the undergraduate and graduate program students of the Laboratory of Research in Pulmonary Physical Therapy (LFIP) who helped in the data collection of this study, and patients with COPD, who kindly agreed to participate in this research.

\section{References}

1. Global Strategy for the Diagnosis, Management, and Prevention of Chronic Obstructive Pulmonary Disease (GOLD). Updated 2018. [acessed out 10, 2018]. Available from http://goldcopd.org/.

2. Spruit MA, Singh SJ, Garvey C, ZuWallack R, Nici L, Rochester C, et al. American Thoracic Society/European Respiratory Society statement on pulmonary rehabilitation. Am J Respir Crit Care Med 2013;188(8):e13-64. 0.1164/ rccm.200508-1211ST

3. O'Donnell DE, Bertley JC, Chau LK, Webb KA. Qualitative aspects of exertional breathlessness in chronic airflow limitation: pathophysiologic mechanisms. Am J Respir Crit Care Med 1997;155(1):109-15.

4. Casanova C, Marin JM, Martinez-Gonzalez C, de LucasRamos P, Mir-Viladrich I, Cosio B, et al. Differential Effect of Modified Medical Research Council Dyspnea, COPD Assessment Test, and Clinical COPD Questionnaire for Symptoms Evaluation Within the New GOLD Staging and Mortality in COPD. Chest 2015;148(1):159-68. doi: 10.1378/ chest.14-2449.

5. Vestbo J, Prescott E, Almdal T, Dahl M, Nordestgaard BG, Andersen T, et al. Body mass, fat-free body mass, and prognosis in patients with chronic obstructive pulmonary disease from a random population sample: findings from the Copenhagen City Heart Study. Am J Respir Crit Care Med 2006;173(1):79-83.
6. Landbo C, Prescott E, Lange P, Vestbo J, Almdal TP. Prognostic value of nutritional status in chronic obstructive pulmonary disease. Am J Respir Crit Care Med 1999;160(6):1856-61.

7. Cote CG, Pinto-Plata V, Kasprzyk K, Dordelly LJ, Celli BR. The 6-min walk distance, peak oxygen uptake, and mortality in COPD. Chest 2007;132(6): 1778-1785.

8. Furlanetto KC, Donaria L, Schneider LP, Lopes JR, Ribeiro $\mathrm{M}$, Fernandes KB, et al. Sedentary behavior is an independent predictor of mortality in subjects with COPD. Respir Care 2017;62(5):579-88. doi: 10.4187/respcare.05306.

9. Celli BR, Cote CG, Marin JM, Casanova C, Montes DO, Mendez RA, et al. The body-mass index, airflow obstruction, dyspnea, and exercise capacity index in chronic obstructive pulmonary disease. N Engl J Med 2004;350(10):1005-1012.

10. Chronic respiratory diseases. COPD predicted to be third leading cause of death in 2030. World Health Organization. [accessed out 18, 2018]. Available from: http://www.who.int/ respiratory/copd/burden/en/.

11. Miller MR, Hankinson J, Brusasco V, Burgos F, Casaburi R, Coates A, et al. Standardisation of spirometry. Eur Respir J 2005;26(2):319-338.

12. Pereira C, Sato T, Rodrigues S. Novos valores de referência para espirometria forçada em brasileiros da raça branca. J Bras Pneumol 2007;33(4):397-406.

13. Price KL, Earthman CP. Update on body composition tools in clinical settings: computed tomography, ultrasound, and bioimpedance applications for assessment and monitoring. Eur J Clin Nutr 2019;73(2):187-93. doi: 10.1038/s41430018-0360-2.

14. Holland AE, Spruit MA, Troosters T, Puhan MA, Pepin V, Saey D, et al. An official European Respiratory Society/ American Thoracic Society technical standard: field walking tests in chronic respiratory disease. Eur Respir $\mathbf{J}$ 2014;44(6):1428-46. doi: 10.1183/09031936.00150314

15. Britto RR, Probst VS, de Andrade AF, Samora GA, Hernandes NA, Marinho PE, et al. Reference equations for the sixminute walk distance based on a Brazilian multicenter study. Braz J Phys Ther 2013;17(6):556-563.

16. Singh SJ, Morgan MD, Scott S, Walters D, Hardman AE. Development of a shuttle walking test of disability in patients with chronic airways obstruction. Thorax 1992;47(12):10191024.

17. Probst VS, Hernandes NA, Teixeira DC, Felcar JM, Mesquita $\mathrm{RB}$, Goncalves CG, et al. Reference values for the incremental shuttle walking test. Resp Med 2012;106(2):243-248.

18. Kovelis D, Segretti NO, Probst VS, Lareau SC, Brunetto AF, Pitta F. Validation of the Modified Pulmonary Functional Status and Dyspnea Questionnaire and the Medical Research Council scale for use in Brazilian patients with chronic obstructive pulmonary disease. J Bras Pneumol 2008;34(12):1008-1018.

19. Cavalheri V, Donaria L, Ferreira T, Finatti M, Camillo CA, Cipulo Ramos EM, et al. Energy expenditure during daily activities as measured by two motion sensors in patients with COPD. Respir Med 2011;105(6):922-929.

20. Gore S, Blackwood J, Guyette M, Alsalaheen B. Validity and reliability of accelerometers in patients with COPD: a systematic review. J Cardiopulm Rehabil Prev 2018;38(3):147-58. doi: 10.1097/HCR.0000000000000284.

21. Demeyer H, Burtin C, Van Remoortel H, Hornikx M, Langer $\mathrm{D}$, Decramer M, et al. Standardizing the analysis of physical 
activity in patients with COPD following a pulmonary rehabilitation program. Chest 2014;146(2):318-27.

22. Sedentary Behaviour Research N. Letter to the editor: standardized use of the terms "sedentary" and "sedentary behaviours". Appl Physiol Nutr Metab 2012;37(3):540-2.

23. Ramon MA, Ter Riet G, Carsin AE, Gimeno-Santos E, Agustí A, Antó JM, et al. The dyspnoea-inactivity vicious circle in COPD: development and external validation of a conceptual model. Eur Respir J 2018;15;52(3). doi: 10.1183/13993003.00079-2018.

24. Gouzi F, Préfaut C, Abdellaoui A, Vuillemin A, Molinari $\mathrm{N}$, Ninot $\mathrm{G}$, et al. Evidence of an early physical activity reduction in chronic obstructive pulmonary disease. Arch Phys Med Rehabil 2011;92(10):1611-1617

25. Maltais F, Decramer M, Casaburi R, Barreiro E, Burelle Y, Debigare R, et al. An official American Thoracic Society/ European Respiratory Society statement: update on limb muscle dysfunction in chronic obstructive pulmonary disease.
Am J Respir Crit Care Med 2014;189(9):e15-62.

26. Fernandes AC, Bezerra OM. Nutrition therapy for chronic obstructive pulmonary disease and related nutritional complications. J Bras Pneumol 2006;32(5):461-471.

27. Tremblay MS, Colley RC, Saunders TJ, Healy GN, Owen N. Physiological and health implications of a sedentary lifestyle. Appl Physiol Nutr Metab 2010;35(6):725-740.

28. Rodrigues A, Camillo CA, Furlanetto KC, Paes T, Morita AA, Spositon T. Cluster analysis identifying patients with COPD at higt risk of 2-year all-cause mortality. Chron Respir Dis 2019;16:1479972318809452.

29. Casanova C, Celli BR, Barria P, Casas A, Cote C, de Torres JP, et al. The 6-min walk distance in healthy subjects: reference standards from seven countries. Eur Respir J 2011;37(1):1506. 